\title{
Uptake of a fluorescently tagged chloroquine analogue is reduced in CQ-resistant compared to CQ-sensitive Plasmodium falciparum parasites
}

Sarah J. Reiling and Petra Rohrbach* ${ }^{*}$

\begin{abstract}
Background: Chloroquine (CQ) was the drug of choice for decades in the treatment of falciparum malaria until resistance emerged. CQ is suggested to accumulate in the parasite's digestive vacuole (DV), where it unfolds its anti-malarial properties. Discrepancies of CQ accumulation in CQ-sensitive (CQS) and CQ-resistant (CQR) strains are thought to play a significant role in drug susceptibility. Analysis of CQ transport and intracellular localization using a fluorescently tagged CQ analogue could provide much needed information to distinguish susceptible from resistant parasite strains. The fluorescently tagged $\mathrm{CQ}$ analogue LynxTag- $\mathrm{CQ}^{\mathrm{TM}}{ }_{\text {GREEN }}\left(\mathrm{CQ}_{\mathrm{GREEN}}\right)$ is commercially available and was assessed for its suitability.
\end{abstract}

Methods: $I_{50}$ values were determined for both $C Q$ and $\mathrm{CQ}_{\text {GREEN }}$ in two $\mathrm{CQS}$ and two CQR Plasmodium falciparum strains. Buffer solutions with varying $\mathrm{pH}$ were used to determine $\mathrm{pH}$-dependent localization of $\mathrm{CQ}_{\mathrm{GREEN}}$ in infected red blood cells. Before CQS or CQR parasites were exposed to different $\mathrm{pH}$ buffers, they were pre-loaded with varying concentrations of $\mathrm{CQ}_{\mathrm{GREEN}}$ for up to $7 \mathrm{~h}$. Intracellular accumulation was analysed using live cell confocal microscopy. $\mathrm{CQ}_{\text {GREEN }}$ uptake rates were determined for the cytosol and $\mathrm{DV}$ in the presence and absence of verapamil.

Results: In CQS strains, twofold higher $I C_{50}$ values were determined for the $\mathrm{CQ}_{G R E E N}$ analogue compared to CQ. No significant differences in $I_{50}$ values were observed in $C Q R$ strains. Addition of verapamil reversed drug resistance of $C Q R$ strains to both $C Q$ and $C Q_{G R E E N}$. Live cell imaging revealed that $C_{G R E E N}$ fluorescence was mainly seen in the cytosol of most parasites, independent of the concentration used. Incubation periods of up to $7 \mathrm{~h}$ did not influence intracellular localization of $\mathrm{CQ}_{\text {GREEN }}$. Nevertheless, $\mathrm{CQ}_{\text {GREEN }}$ uptake rates in $\mathrm{CQR}$ strains were reduced by $50 \%$ compared to CQS strains.

Conclusion: Although fluorescence of $\mathrm{CQ}_{\text {GREEN }}$ was mainly seen in the cytosol of parasites, $\mathrm{IC}_{50}$ assays showed comparable efficacy of $C_{\text {GREEN }}$ and $C Q$ in parasite killing of CQS and $C Q R$ strains. Reduced uptake rates of $C_{G R E E N}$ in $C Q R$ strains compared to CQS strains indicate parasite-specific responses to $C_{\text {GREEN }}$ exposure. The data contains valuable information when $\mathrm{CQ}_{\mathrm{GREEN}}$ is used as an analogue for $\mathrm{CQ}$.

Keywords: LynxTag- $\mathrm{CQ}_{\mathrm{GREEN}}$, Live cell imaging, Malaria, Antimalarial drugs, Chloroquine resistant, Chloroquine sensitive

*Correspondence: petra.rohrbach@mcgill.ca

Institute of Parasitology, McGill University, Ste. Anne de Bellevue,

Montreal, QC H9X-3V9, Canada

(c) The Author(s) 2019. This article is distributed under the terms of the Creative Commons Attribution 4.0 International License (http://creativecommons.org/licenses/by/4.0/), which permits unrestricted use, distribution, and reproduction in any medium, provided you give appropriate credit to the original author(s) and the source, provide a link to the Creative Commons license, and indicate if changes were made. The Creative Commons Public Domain Dedication waiver (http://creativecommons.org/ publicdomain/zero/1.0/) applies to the data made available in this article, unless otherwise stated. 


\section{Background}

Plasmodium falciparum is the main causative agent of malaria, killing hundreds of thousands of people annually [1]. Resistance to anti-malarial drugs is widespread, and promising anti-malarial drugs that are effective and affordable for people with low income are slow in development. For decades, chloroquine (CQ) was the safest, most affordable and effective drug against malaria, saving the lives of millions of people until resistance emerged [2]. To date, its mode of action is still not fully understood. Some researchers suggest that CQ could have more than one intracellular target, making it more difficult for parasites to develop resistance [3-5].

To effectively use CQ as an anti-malarial treatment in areas where CQ resistance has been reported, it is imperative to gain more insight into its mechanism of action. The small size and uncharged form of CQ at neutral $\mathrm{pH}$ makes it difficult to use for molecular biological experiments to determine its accumulation in intracellular compartments or its affinity to other molecules.

Chloroquine transport studies have mainly been performed using radiolabelled CQ [6-8]. The great advantage of this method is that the intrinsic properties of CQ remain unaltered. However, it is not possible to study intracellular distribution and trafficking of radiolabelled CQ in intact parasites. Therefore, fluorescently labelled CQ analogues provide a new means to evaluate intracellular activity of this drug. To date, there are two fluorescently labelled chloroquine analogues commercially available: LynxTag-CQ ${ }^{\mathrm{TM}}{ }_{\text {BLUE }}$ and LynxTag-CQ ${ }^{\mathrm{TM}}$ GREEN (BioLynx Technologies, Singapore, Singapore). While the literature cites that $C_{B L U E}$ was mainly found to be fluorescent in the parasite cytosol [9-11], only one study has been published with $\mathrm{CQ}_{\text {GREEN }}$. This study showed $\mathrm{CQ}_{\text {GREEN }}$ accumulation in the DV of CQ-sensitive (CQS) P. falciparum parasites and yeast-derived microsomes expressing the P. falciparum chloroquine resistance transporter (PfCRT) [12].

For this study, $\mathrm{CQ}_{\mathrm{GREEN}}$ was compared to unmodified $C Q$ and investigated whether the fluorescently tagged CQ analogue can be used to obtain insight into intracellular CQ trafficking and localization. A better knowledge of the differences in CQ accumulation, distribution, uptake and efflux between CQS and CQresistant (CQR) strains is imperative to understand drug resistance. The findings show that, although CQ and $\mathrm{CQ}_{\text {GREEN }}$ show comparable $\mathrm{IC}_{50}$ values in $\mathrm{CQS}$ and $C Q R$ parasites, discrepancies were seen between $\mathrm{CQ}_{\text {GREEN }}$ and unmodified CQ in their expected intracellular localization. A strong $\mathrm{CQ}_{\mathrm{GREEN}}$ fluorescence was mainly seen in the cytosol of both CQS and CQR strains.

\section{Methods}

\section{Parasite strains and culture conditions}

Two CQS (3D7, HB3) and two CQR (FCB, Dd2) strains were used for all experiments. Parasites were cultured continuously, as described by Trager and Jensen [13], with modifications. Briefly, parasites at 5\% haematocrit were propagated in culture medium containing RPMI 1640 (Life Technologies, Burlington, ON, Canada) supplemented with $25 \mathrm{mM}$ HEPES, $2 \mathrm{mM}$ L-glutamine, gentamicin $(20 \mu \mathrm{g} / \mathrm{ml})$ (Life Technologies, Burlington, ON, Canada), $100 \mu \mathrm{M}$ hypoxanthine (Sigma-Aldrich, Oakville, ON, Canada), and 0.5\% AlbuMAX I (Life Technologies, Burlington, ON, Canada). Parasites were maintained at $37{ }^{\circ} \mathrm{C}$ with an atmosphere of $5 \% \mathrm{CO}_{2}, 3 \% \mathrm{O}_{2}$ and $92 \% \mathrm{~N}_{2} . \mathrm{A}^{+}$red blood cells were obtained from the Interstate Blood Bank (Memphis, TN, USA). Giemsa-stained blood smears were prepared daily to monitor parasite growth. For synchronization, parasites were treated with 5\% D-sorbitol (BioShop Canada, Burlington, ON, Canada) for $10 \mathrm{~min}$ at $37{ }^{\circ} \mathrm{C}$; sorbitol was removed and parasites were washed once before returning them back into culture.

\section{Cytotoxicity assays}

Cytotoxicity assays were performed as described previously [14-17], with modifications. Cultures of $0.5 \%$ parasitaemia and $2 \%$ haematocrit were incubated in $100 \mu \mathrm{l}$ culture medium per well in a 96-well plate assay. A drug dilution series of 1:3 was prepared, starting with $1 \mu \mathrm{M}$ as highest substrate concentration. Plates were incubated at $37{ }^{\circ} \mathrm{C}, 5 \% \mathrm{CO}_{2}$ and $3 \% \mathrm{O}_{2}$ for $72 \mathrm{~h}$, then frozen and stored at $-80^{\circ} \mathrm{C}$.

Readouts of the assay were performed using the SYBR Green I detection method. For this, plates were thawed at room temperature and $100 \mu \mathrm{l} 2 \times$ lysis buffer $(20 \mathrm{mM}$ Tris pH 7.5, 5 mM EDTA, 0.008\% saponin, 0.08\% Triton $\mathrm{X}-100$, and $0.2 \mu \mathrm{l} \mathrm{SYBR}$ Green $\mathrm{I} / \mathrm{ml}$ ) was added to each well. Plates were incubated in the dark for at least $1 \mathrm{~h}$. Fluorescence intensity was determined using a Synergy H4 plate reader (Fisher Scientific, Nepean, ON, Canada) with $485 \mathrm{~nm}$ excitation and $520 \mathrm{~nm}$ emission wavelengths. $\mathrm{IC}_{50}$ values were determined by fitting concentration response curves with a custom-made procedure for IGOR Pro 6.2 based on a R script kindly provided by Le Nagard $[18,19]$.

\section{Fluorescence of $\mathrm{CQ}_{\mathrm{GREEN}}$ at varying $\mathrm{pH}$}

To determine if fluorescence intensity of $\mathrm{CQ}_{\text {GREEN }}$ is altered at varying $\mathrm{pH}$, buffer solutions were prepared ranging from $\mathrm{pH}$ 5.0-8.0 based on a modified Ringer's solution $\left(122.5 \mathrm{mM} \mathrm{NaCl}, 5.4 \mathrm{mM} \mathrm{KCl}, 1.2 \mathrm{mM} \mathrm{CaCl}_{2}\right.$, $0.8 \mathrm{mM} \mathrm{MgCl}_{2}, 11 \mathrm{mM} \mathrm{D}$-glucose). Buffer solutions 
contained $10 \mathrm{mM}$ MES for $\mathrm{pH}$ 5.0-6.5 or $10 \mathrm{mM}$ HEPES for $\mathrm{pH}$ 7.0-8.0. In a 96-well plate, $100 \mu \mathrm{l}$ buffer solutions of varying $\mathrm{pH}$ containing $1 \mu \mathrm{M} \mathrm{CQ}_{\mathrm{GREEN}}$ were prepared in triplicate. Fluorescence intensity was measured at $37{ }^{\circ} \mathrm{C}$ using the Synergy H4 fluorimeter (Bio-Tek, Winooski, VT, USA). Excitation spectra ranging from 400 to $520 \mathrm{~nm}$ were measured with fixed emission at $540 \mathrm{~nm}$, and emission spectra ranging from 500 to $630 \mathrm{~nm}$ were measured with fixed excitation at $488 \mathrm{~nm}$. Quantification was done using Microsoft Excel 2013.

\section{Live cell imaging}

Intracellular $\mathrm{CQ}_{\mathrm{GREEN}}$ accumulation at different concentration and $\mathrm{pH}$ was analysed in intact parasitized red blood cells. For this, 3D7 trophozoite stage parasites were incubated for $30 \mathrm{~min}$ at $37{ }^{\circ} \mathrm{C}$ with 25, 50, $500 \mathrm{nM}$ or $2.5 \mu \mathrm{M} \mathrm{CQ}_{\mathrm{GREEN}}$ in Ringer's solution with $\mathrm{pH} 7.4$ or buffer solutions with $\mathrm{pH} 7.2$ or 5.2. Images were taken using a $488 \mathrm{~nm}$ argon laser $(12.5 \mathrm{~mW}, 0.8 \%)$ on a Zeiss LSM 710 confocal microscope (Carl Zeiss, Oberkochen, Germany) equipped with a water-corrected objective (C-apochromat $63 \times / 1.20 \mathrm{~W}$ Korr M27). Emission range was set to $500-600 \mathrm{~nm}$. Localization of $\mathrm{CQ}_{\text {GREEN }}$ within the parasite under various $\mathrm{pH}$ conditions was determined using the ZEN 2010 software (Carl Zeiss Microlmaging, Oberkochen, Germany).

For long-term incubation with $\mathrm{CQ}_{\mathrm{GREEN}}$, early trophozoite stage 3D7 parasites were incubated with $100 \mathrm{nM}$,

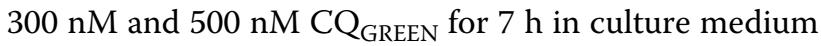
at $37{ }^{\circ} \mathrm{C}, 3 \% \mathrm{O}_{2}, 5 \% \mathrm{CO}_{2}$. Parasites were then transferred onto a microscope chamber and imaged using a Zeiss LSM 710 confocal microscope (Carl Zeiss, Oberkochen, Germany), a $63 \times$ water corrected objective (C-apochromat $63 \times / 1.20 \mathrm{~W}$ Korr M27) and a $488 \mathrm{~nm}$ laser $(12.5 \mathrm{~mW}, 0.8 \%)$. Emission range was set to $500-$ $600 \mathrm{~nm}$. A constant temperature of $37^{\circ} \mathrm{C}$ was maintained during the measurements using a stage-top incubator (Tokai Hit, Shizuoka-ken, Japan). Images were analysed with the ZEN 2010 software (Carl Zeiss MicroImaging, Oberkochen, Germany).

To analyse $\mathrm{CQ}_{\mathrm{GREEN}}$ uptake of CQS and CQR strains, synchronized trophozoite stage parasites were washed in Ringer's solution and transferred onto a microscope chamber. Parasites were allowed to settle for $5 \mathrm{~min}$, then the solution was aspirated and replaced with new

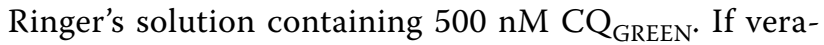
pamil was added, parasites were preincubated with $1 \mu \mathrm{M}$ VP for $15 \mathrm{~min}$ at $37{ }^{\circ} \mathrm{C}$, then transferred onto a microscope chamber. For the time lapse measurement, $500 \mathrm{nM} \mathrm{CQ} \mathrm{QRREEN}_{\text {were }}$ added to the Ringer's solution with or without $1 \mu \mathrm{M}$ VP. Images were taken every $3 \mathrm{~s}$ for a time span of $500 \mathrm{~s}$ using a Zeiss LSM 710 confocal microscope (Carl Zeiss, Oberkochen, Germany) and a $63 \times$ water corrected objective (C-apochromat $63 \times / 1.20 \mathrm{~W}$ Korr M27). Excitation was done using a $488 \mathrm{~nm}$ laser $(12.5 \mathrm{~mW}, 0.8 \%)$, and an emission range from 500 to $600 \mathrm{~nm}$. Regions of interest (ROI) were set for the parasite cytosol, DV, infected RBC cytosol and uninfected RBC. Fluorescence of ROIs was determined for each time point using ImageJ 1.47q (National Institutes of Health, USA). Uptake rates were calculated for the cytosol and DV during the saturation phase and analysed using IGOR Pro 6.2 by fitting influx to $f=\mathrm{y}_{0}+\mathrm{a}\left(1-\mathrm{e}^{-\mathrm{bx}}\right)$ and initial rates $\left(\mathrm{v}_{0}\right)$ to $\mathrm{y}=\mathrm{mx}+\mathrm{b}$, as described previously [20]. Graphs were created using IGOR Pro 6.2.

\section{Results $\mathrm{IC}_{50}$ determination of $\mathrm{CQ}$ and $\mathrm{CQ}_{\text {GREEN }}$ in $\mathrm{CQS}$ and $\mathrm{CQR}$ parasite strains}

To evaluate the efficacy of the fluorescently tagged chloroquine analogue $C_{\text {GREEN }}$, the half maximal inhibitory concentrations $\left(\mathrm{IC}_{50}\right)$ were determined using the SYBR Green I detection assay and a standardized calculation method for data analysis in two CQS and two CQR P. falciparum strains (Table 1) [19]. The two CQS strains 3D7 and HB3 had a CQ $\mathrm{IC}_{50}$ of $24 \pm 6 \mathrm{nM}$ and $14 \pm 1 \mathrm{nM}$, respectively. Compared to exposure to $\mathrm{CQ}, \mathrm{IC}_{50}$ values doubled in both $\mathrm{CQ}_{\mathrm{GREEN}}$ treated $3 \mathrm{D} 7$ $(48 \pm 3 \mathrm{nM}, \mathrm{p}=0.02)$ and in HB3 parasites $(36 \pm 8 \mathrm{nM}$, $\mathrm{p}=0.06$ ). Treatment of the CQR strains FCB and Dd2 showed similar $\mathrm{IC}_{50}$ values for all tested drugs. $\mathrm{IC}_{50}$ values of $166 \pm 9 \mathrm{nM}$ for CQ and $177 \pm 43 \mathrm{nM}$ for $C_{\text {GREEN }}$ were determined in $\mathrm{FCB}(\mathrm{p}=0.81)$. For $\mathrm{Dd} 2, \mathrm{IC}_{50}$ values of $169 \pm 4 \mathrm{nM}$ were obtained for CQ and $174 \pm 27 \mathrm{nM}$ for $\mathrm{CQ}_{\mathrm{GREEN}}(\mathrm{p}=0.85)$. Resistance in CQR strains could be reversed with the addition of $1 \mu \mathrm{M}$ VP. For FCB, $\mathrm{IC}_{50}$ values were $41 \pm 7$ for $\mathrm{CQ}+\mathrm{VP}$ and $30 \pm 4$ for $\mathrm{CQ}_{\mathrm{GREEN}}+\mathrm{VP}$. For $\mathrm{Dd} 2, \mathrm{IC}_{50}$ values were $53 \pm 7$ for $\mathrm{CQ}+\mathrm{VP}$ and $35 \pm 6$ for $\mathrm{CQ}_{\mathrm{GREEN}}+\mathrm{VP}$. No significant changes were observed in CQS strains for treatment with $\mathrm{CQ}$ or $\mathrm{CQ}_{\mathrm{GREEN}}$ in combination with verapamil.

\begin{tabular}{|c|c|c|c|c|}
\hline Strain & $\mathrm{CQ}$ & $\mathrm{CQ}+\mathrm{VP}$ & $\mathrm{CQ}_{\text {GREEN }}$ & $\mathrm{CQ}_{\mathrm{GREEN}}+\mathrm{VP}$ \\
\hline 3D7 & $24 \pm 6$ & $17 \pm 1$ & $48 \pm 3$ & $50 \pm 3$ \\
\hline HB3 & $14 \pm 1$ & $19 \pm 2$ & $36 \pm 8$ & $36 \pm 7$ \\
\hline $\mathrm{FCB}$ & $166 \pm 9$ & $41 \pm 7$ & $177 \pm 43$ & $30 \pm 4$ \\
\hline $\mathrm{Dd} 2$ & $169 \pm 4$ & $53 \pm 7$ & $174 \pm 27$ & $35 \pm 6$ \\
\hline
\end{tabular}

All values are given in $\mathrm{nM} \pm \mathrm{SEM}$ and represent three independent experiments with or without $1 \mu \mathrm{M}$ VP

$V P$ verapamil 


\section{Fluorescence intensity of $\mathrm{CQ}_{\mathrm{GREEN}}$ is dependent on $\mathrm{pH}$} $\mathrm{pH}$ is known to affect the fluorescence intensity and excitability of a molecule [21]. While some fluorophores have stable emission at different $\mathrm{pH}$, others are more $\mathrm{pH}$ sensitive $[22,23]$. This must be considered when comparing fluorescence intensity of a fluorochrome in intracellular compartments with significantly different $\mathrm{pH}$, as is the case for the parasite's cytosol (at approx. pH 7.1) and DV (at approx. $\mathrm{pH}$ 5.2) [24]. $\mathrm{CQ}_{\mathrm{GREEN}}$ consists of a chloroquine analogue tagged with a Bodipy fluorophore, which is relatively insensitive to solvent polarity and $\mathrm{pH}$ [25]. To determine if this fluorescently tagged CQ is $\mathrm{pH}$ dependent, $\mathrm{CQ}_{\mathrm{GREEN}}$ fluorescence was tested using buffer solutions containing HEPES or MES to obtain $\mathrm{pH}$ values ranging from 5.0 to 8.0. These buffer solutions were used to evaluate possible changes in fluorescence intensity seen in the parasite cytosol, having a physiological $\mathrm{pH}$ of 7.2 , and the digestive vacuole, maintaining a $\mathrm{pH}$ of 5.2 [24]. Excitation spectra for $\mathrm{CQ}_{\text {GREEN }}$ showed constant fluorescence intensity at a fixed emission of $540 \mathrm{~nm}$ (Fig. 1a). The $\mathrm{CQ}_{\text {GREEN }}$ excitation peak was determined at $508 \mathrm{~nm}$. Since live cell imaging will be performed using a $488 \mathrm{~nm}$ laser for excitation, $\mathrm{CQ}_{\text {GREEN }}$ emission spectra were measured at different $\mathrm{pH}$ with a fixed excitation wavelength of $488 \mathrm{~nm} . \mathrm{CQ}_{\mathrm{GREEN}}$ emission intensity peaked at $522 \mathrm{~nm}$ and increased 1.6-fold from 13,698 RFU at pH 7.5 to 22,419 RFU at pH 5.5 (Fig. 1b). Therefore, somewhat higher $C_{\text {GREEN }}$ fluorescence is emitted in acidic compartments compared to neutral compartments at equal intracellular $\mathrm{CQ}_{\mathrm{GREEN}}$ concentrations.

\section{$\mathrm{CQ}_{\text {GREEN }}$ accumulates in the parasite cytosol}

The weak base properties of chloroquine and its diprotonation at low $\mathrm{pH}$ result in its high accumulation in the parasite's digestive vacuole [26]. Addition of a fluorescent group (here Bodipy) to chloroquine could alter the intracellular distribution of this molecule. In this study, the CQS strain 3D7 was treated with $25 \mathrm{nM}, 50 \mathrm{nM}, 500 \mathrm{nM}$ and 2.5 $\mu \mathrm{M} \mathrm{CQ}_{\mathrm{GREEN}}$ in Ringer's solution, or buffer solutions with $\mathrm{pH} 7.2$ and $\mathrm{pH}$ 5.2, respectively. $\mathrm{CQ}_{\text {GREEN }}$ uptake and intracellular distribution was monitored in 5 min intervals for a total of $30 \mathrm{~min}$ at $37^{\circ} \mathrm{C}$. Increasing $\mathrm{CQ}_{\text {GREEN }}$ concentrations resulted in stronger fluorescence signals, independent of the buffer solution used (Fig. 2). The fluorescence signal was always stronger in the cytosol compared to the DV. Faint accumulation of $\mathrm{CQ}_{\text {GREEN }}$ in the digestive vacuole was observed with all buffer solutions and $\mathrm{CQ}_{\mathrm{GREEN}}$ concentrations.

Although CQ is expected to accumulate in the parasite's DV within minutes, addition of $\mathrm{CQ}_{\mathrm{GREEN}}$ was extended for up to $7 \mathrm{~h}$ in $3 \mathrm{D} 7$ parasites at $37{ }^{\circ} \mathrm{C}, 3 \% \mathrm{O}_{2}$, $5 \% \mathrm{CO}_{2}, 92 \% \mathrm{~N}_{2}$. It was previously reported that incubation of the chloroquine analogue $\mathrm{CQ}_{\mathrm{BLUE}}$ at a $3 \mu \mathrm{M}$ concentration for $8 \mathrm{~h}$ resulted in nonspecific localization throughout the parasite's cytosol, while accumulation of $\mathrm{CQ}_{\text {BLUE }}$ in the DV was detected using a concentration of $300 \mathrm{nM}$ [9]. Therefore, for this study, $\mathrm{CQ}_{\mathrm{GREEN}}$ concentrations ranging from 100 to $500 \mathrm{nM}$ were used. Fluorescence signals obtained after $7 \mathrm{~h}$ incubation were low for all tested $C_{\text {GREEN }}$ concentrations (Fig. 3). Accumulation of $C Q_{\text {GREEN }}$ in the DV could be detected in very few parasites (approx. 5\%) (Fig. 3b+d). Furthermore, accumulation of $\mathrm{CQ}_{\mathrm{GREEN}}$ in the DV was only seen in one parasite of a double-infected red blood cell (RBC) (Fig. 3b),
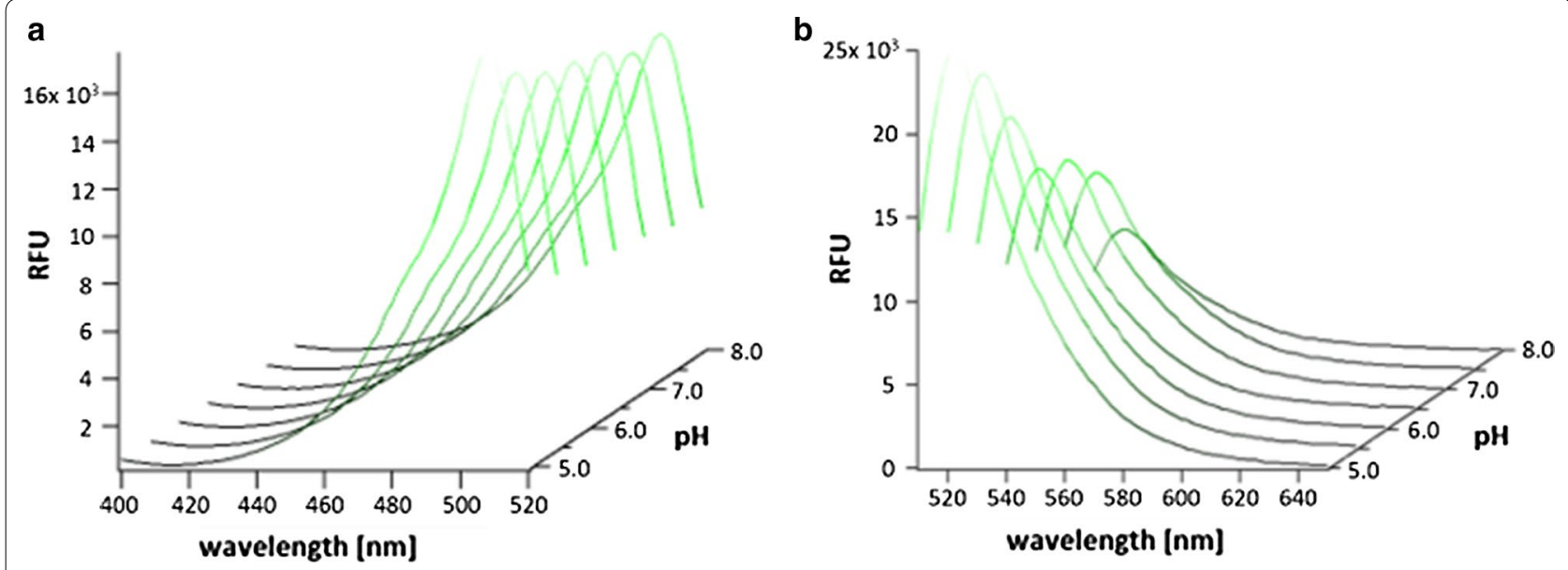

Fig. $1 \mathrm{CQ}_{\mathrm{GREEN}}$ excitation and emission spectra at varying $\mathrm{pH}$. Solutions with varying $\mathrm{pH}$ ranging from 5 to 8 , each containing $1 \mu \mathrm{M} C \mathrm{CQ}_{\mathrm{GREEN}}$ were prepared in triplicate and measured using a fluorimeter. Temperature was set to $37^{\circ} \mathrm{C}$ during measurements. a Excitation spectra with fixed emission at $540 \pm 4.5 \mathrm{~nm}$. b Emission spectra with fixed excitation at $488 \pm 4.5 \mathrm{~nm}$ 


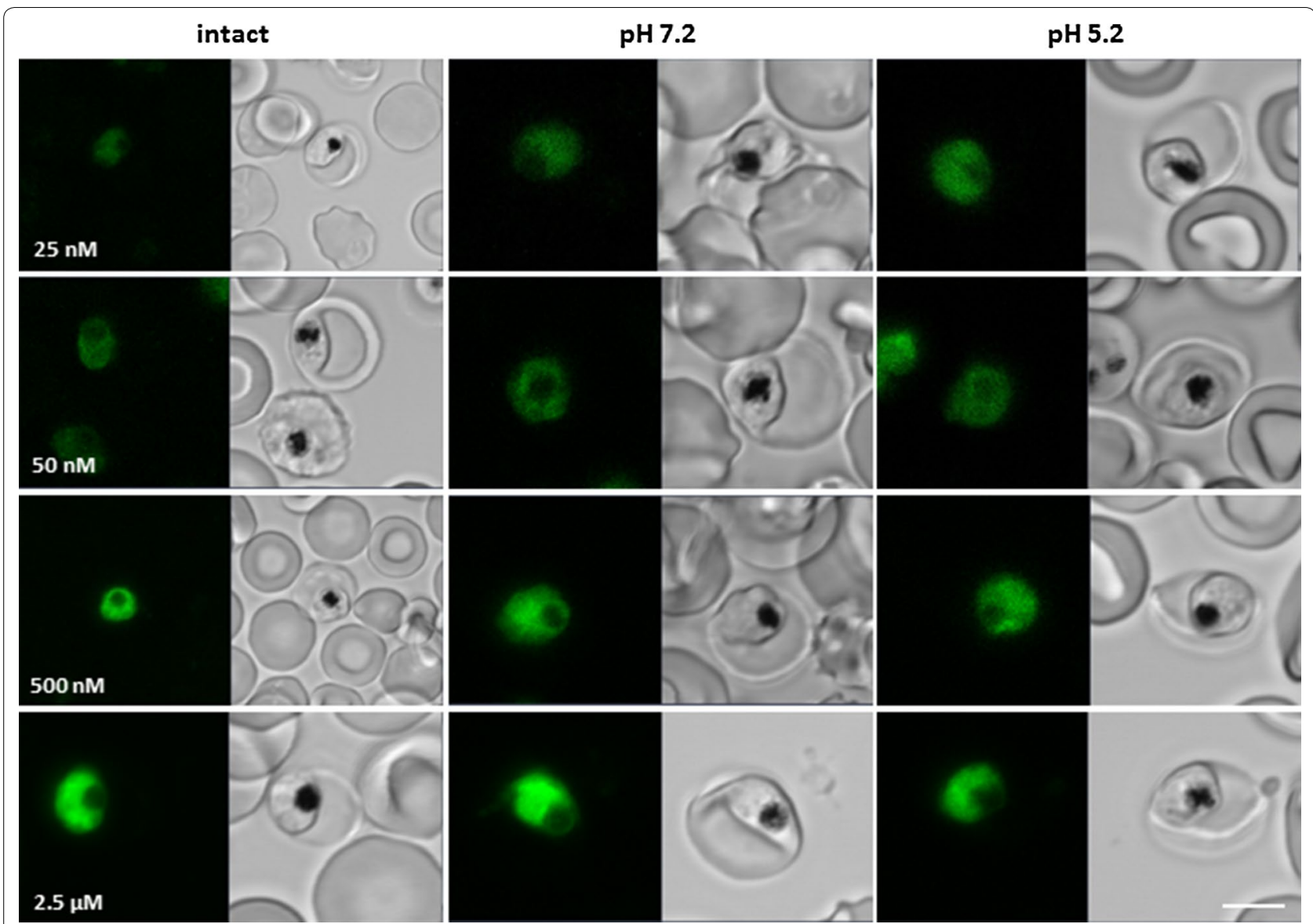

Fig. 2 Live cell imaging of $\mathrm{CQ}_{\text {GREEN }}$ treated parasites. Synchronized trophozoite stage 3D7 parasites containing Ringer's or Equilibration Buffer solution for pH 7.2 and 5.2 were prepared for confocal microscopy. Different $\mathrm{CQ}_{\text {GREEN }}$ concentrations were added and uptake was monitored for $30 \mathrm{~min}$, while emission range was set to $500-600 \mathrm{~nm}$. Fluorescence increased with higher $\mathrm{CQ}_{\mathrm{GREEN}}$ concentrations but no accumulation of $\mathrm{CQ}_{\mathrm{GREEN}}$ could be detected in the parasite's DV. Scale bar, $5 \mu \mathrm{m}$

suggesting that $\mathrm{CQ}_{\mathrm{GREEN}}$ accumulation in the $\mathrm{DV}$ is not equally achieved in individual parasites. Moreover, the $\mathrm{CQ}_{\mathrm{GREEN}}$ fluorescence in the DV of the parasite in Fig. 3b is only 2.8 -fold higher compared to the cytosol, which is much lower than expected.

\section{Stability of $\mathrm{CQ}_{\mathrm{GREEN}}$ compound}

Next, it was investigated if the Bodipy moiety of $\mathrm{CQ}_{\text {GREEN }}$ is cleaved and remains in the cytosol while CQ reaches the DV, where it can unfold its anti-malarial properties. It was previously demonstrated that cleavage of fluorescent molecules through proteases changes the environment of the reactive center loop, resulting in a spectral shift of the fluorescence peak $[27,28]$. To evaluate if a spectral shift of the fluorescence peak occurs in $\mathrm{CQ}_{\mathrm{GREEN}}$ after exposure to parasite proteases, uninfected or 3D7-infected cultures with a parasitaemia of $2.5 \%, 5 \%$ or $10 \%$ were loaded with $500 \mathrm{nM} \mathrm{CQ} \mathrm{QREEN}_{\text {for }} 1 \mathrm{~h}$. Parasites were then washed to remove excess $C Q_{\text {GREEN }}$ in the supernatant and were lysed before measuring fluorescence. Since live cells were loaded with the dye, any detected signal should be derived from $\mathrm{CQ}_{\mathrm{GREEN}}$ molecules taken up by the parasites. As a control, parasites were with free acid BodipyFL were analysed using the same conditions.

The fluorescence peak for the free acid Bodipy-FL control was measured at $512 \mathrm{~nm}$, while the peak for $\mathrm{CQ}_{\mathrm{GREEN}}$ was measured at $520 \mathrm{~nm}$ (Fig. 4). This fluorescence shift is large enough to differentiate between free Bodipy and Bodipy conjugated to CQ. Treatment of uninfected RBCs (uRBCs) and infected RBCs (iRBCs) with $500 \mathrm{nM}$ Bodipy-FL for $1 \mathrm{~h}$ resulted in low fluorescence in all samples, indicating that Bodipy-FL is not readily accumulating in uRBCs or iRBCs. When parasites were treated with $500 \mathrm{nM} \mathrm{CQ}_{\mathrm{GREEN}}$, a proportional increase in $\mathrm{CQ}_{\mathrm{GREEN}}$ fluorescence was observed with increasing parasitaemia from $0 \%$ (uRBCs) to $10 \%$ (iRBCs), as expected. The fluorescence peak was measured at $520 \mathrm{~nm}$ for $\mathrm{CQ}_{\text {GREEN }}$ in Ringer's solution alone (control) and remained constant 

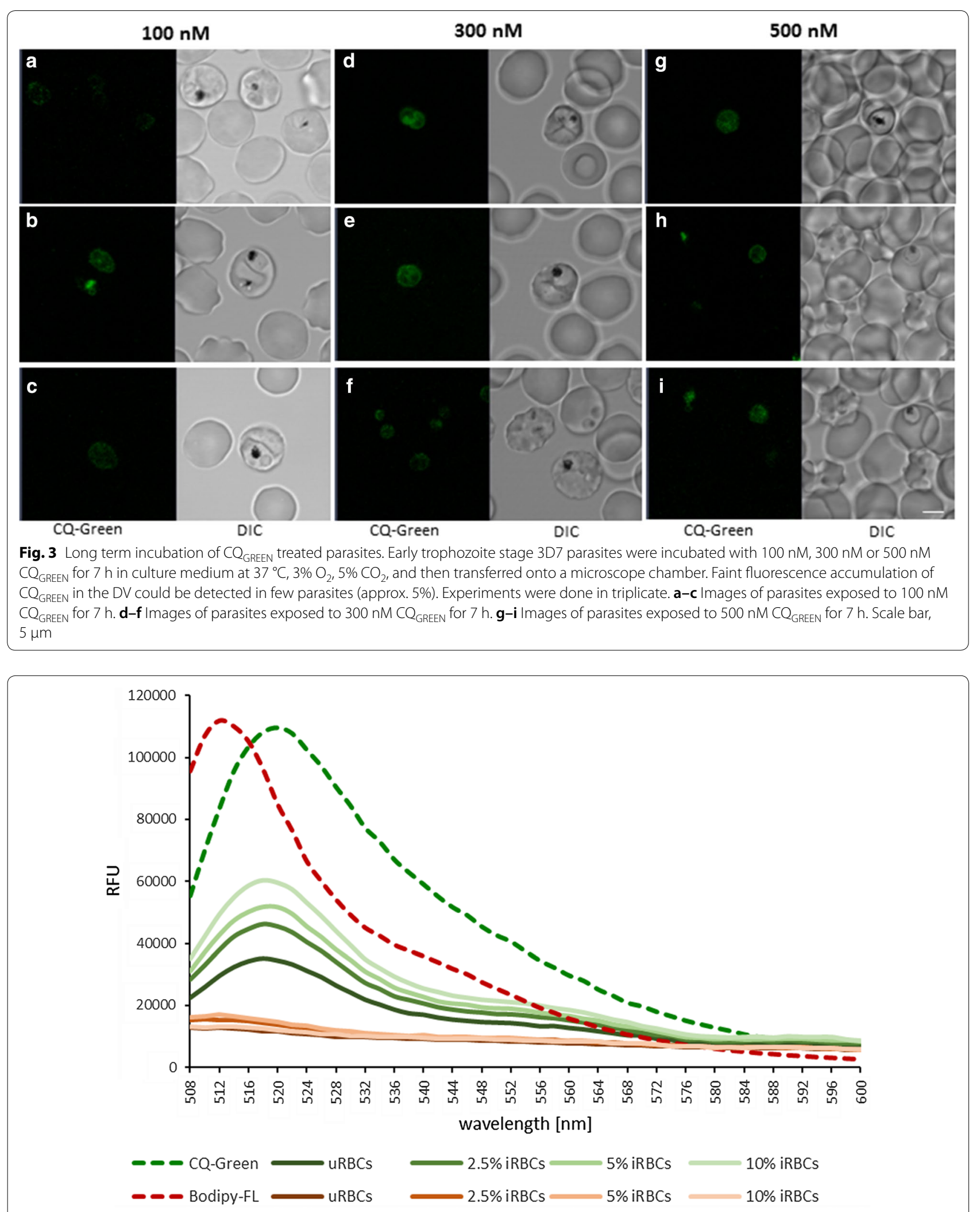

Fig. $4 \mathrm{CQ}_{\mathrm{GREEN}}$ and Bodipy-FL fluorescence. $\mathrm{CQ}_{\text {GREEN }}$ and free acid Bodipy-FL were measured in solution or after incubation with, and lysis of, uninfected red blood cells and red blood cells infected with 3D7 trophozoite stage parasites (URBCs and iRBCs, respectively). No shift of CQ fluorescence towards the Bodipy-FL peak was observed in URBCs and iRBCs. Experiment was done twice in triplicate 
at $518-520 \mathrm{~nm}$ for all $\mathrm{CQ}_{\text {GREEN }}$ treated $\mathrm{uRBC}$ and iRBC samples. Thus, either no cleavage of the Bodipy tag in $\mathrm{CQ}_{\text {GREEN }}$ occurred or the cleaved Bodipy moiety was not retained within the RBCs and a fluorescent signal was only obtained from uncleaved $\mathrm{CQ}_{\mathrm{GREEN}}$.

\section{$\mathrm{CQ}_{\text {GREEN }}$ uptake differs in CQS and CQR strains}

Most researchers focus on CQ accumulation in the DV, suggesting that enhanced CQ efflux from the DV through PfCRT confers drug resistance [29, 30]. CQ uptake in intact iRBCs has mainly been described as passive diffusion and subsequent accumulation in the DV due to the drug's weak base properties [31, 32]. Molecular mechanisms that influence CQ uptake and, therefore, reduce the drug influx in CQR strains compared to CQS strains may have gone unrecognized. $\mathrm{CQ}_{\mathrm{GREEN}}$ offers the possibility to measure uptake in live cells. Although $\mathrm{CQ}_{\mathrm{GREEN}}$ mainly accumulates and fluoresces in the parasite's cytosol, with weak fluorescence in the DV, it was still possible to measure its uptake rate in both compartments.

The rate of $C_{\text {GREEN }}$ uptake was analysed in two CQS strains (3D7 and HB3) and compared with two CQR strains (Dd2 and FCB). Fluorescence was measured from the parasite cytosol, DV, iRBC cytoplasm and uRBC. No increase in $\mathrm{CQ}_{\text {GREEN }}$ fluorescence beyond background levels was observed in the cytoplasm of infected or uninfected RBCs (Fig. 5a). There was a rapid increase in fluorescence in the parasite cytosol and DV in the initial $150 \mathrm{~s}$, followed by a slower, almost linear $\mathrm{CQ}_{\mathrm{GREEN}}$ uptake. This is in agreement with previous studies where they showed that CQ uptake can be separated into a short period of very rapid uptake $(<30 \mathrm{~s})$ followed by a long, slower phase [33], and addition of verapamil did not influence CQ uptake during the initial phase [34].

$\mathrm{CQ}_{\text {GREEN }}$ uptake rate for the parasite cytosol was approx. twofold higher in CQS strains compared to CQR strains (Fig. 5b). For the DV, $\mathrm{CQ}_{\text {GREEN }}$ uptake rates were approx. 2.5-fold higher in CQS strains compared to $\mathrm{CQR}$ strains. $\mathrm{CQ}_{\mathrm{GREEN}}$ uptake rates between CQS and CQR strains were statistically highly significant for both the cytosol $(\mathrm{p}<0.0001)$ and DV $(\mathrm{p}<0.0001)$. Increased $\mathrm{CQ}_{\text {GREEN }}$ uptake rates for the DV of CQS strains suggest that active transport of CQ into the DV occurred in addition to diffusion, which is absent in CQR strains. As expected, addition of verapamil did not influence $\mathrm{CQ}_{\text {GREEN }}$ uptake in the parasite cytosol or DV in all CQR strains tested.

\section{Discussion}

The exact mechanisms responsible for chloroquine resistance have eluded researchers for decades. It has long been described that CQR strains accumulate two to sevenfold less CQ than CQS strains [35]. Nevertheless,
CQR strains are still able to tolerate higher intracellular CQ concentrations than CQS strains before irreversible cell damage occurs $[3,7,33,36]$. Researchers have advocated that inhibition of haemozoin formation by CQ is not sufficient to explain its effect on parasite killing [37]. Furthermore, a possible role of CQ in the parasite's cytosol has also been proposed [5]. A fluorescently labelled CQ analogue could provide insight into the intracellular distribution of CQ that is not attributed to diffusion alone. This study set out to examine CQ uptake in live parasites using $\mathrm{CQ}_{\mathrm{GREEN}}$.

$\mathrm{IC}_{50}$ values were compared in CQS and CQR strains after exposure to $C Q$ or $C_{\text {GREEN }}$. A decrease in the efficacy for $C_{\text {GREEN }}$ may suggest that the $C Q$ analogue does not reach its site of action as efficiently as its native form or binds to its target less efficiently. Calculated $\mathrm{IC}_{50}$ values in CQS strains showed that CQ was twice as effective as $\mathrm{CQ}_{\mathrm{GREEN}}$ in parasite growth inhibition. In comparison, similar $\mathrm{IC}_{50}$ values for $\mathrm{CQ}$ and $\mathrm{CQ}_{\mathrm{GREEN}}$ were determined in CQR strains. In a previous study by Loh and colleagues [12], $\mathrm{IC}_{50}$ values in $3 \mathrm{D} 7$ were approx. fivefold higher for $\mathrm{CQ}_{\text {GREEN }}$ compared to $\mathrm{CQ}$, and nearly doubled in the CQR strain K1. Thus, the parasites used for this study seemed to be more sensitive to $\mathrm{CQ}_{\text {GREEN }}$ exposure than reported in earlier publications. In both studies, drug resistance could be reversed by chemosensitizers such as verapamil, suggesting that $C_{\text {GREEN }}$ 's mode of action is similar to $C Q$.

Although $C_{\text {GREEN }}$ seemed slightly less effective than $\mathrm{CQ}$ in the $\mathrm{IC}_{50}$ assays for CQS strains, its Bodipy fluorescent tag makes it suitable for live cell imaging. This was confirmed by fluorometric readings, where a strong fluorescence emission signal for $\mathrm{CQ}_{\mathrm{GREEN}}$ was measured at a $488 \mathrm{~nm}$ excitation wavelength. Spectral scans showed a strong fluorescence signal at the measured $\mathrm{pH}$ spectrum ranging from $\mathrm{pH} 5-8$ with a moderate increase in fluorescence at acidic $\mathrm{pH}$.

Accumulation of $\mathrm{CQ}_{\text {GREEN }}$ fluorescence was found in only $5 \%$ of the parasite's DV compared to the cytosol during live cell imaging at any of the tested $\mathrm{CQ}_{\text {GREEN }}$ concentrations, ranging from $25 \mathrm{nM}$ to $2.5 \mu \mathrm{M}$. Considering that the $\mathrm{CQ}_{\text {GREEN }} \mathrm{IC}_{50}$ was determined at $24 \mathrm{nM}$, any of the tested concentrations for live cell imaging would have been sufficient to kill the parasites. If $C Q$ and $C_{\text {GREEN }}$ had its primary target in the parasite's DV, as suggested by several studies [38-42], then we would have expected a higher $\mathrm{CQ}_{\mathrm{GREEN}}$ fluorescence in the DV.

Protonation of $\mathrm{CQ}$, or its analogues, influence their membrane permeability and thus their intracellular distribution [43, 44]. Treatment of intact $P$. falciparuminfected erythrocytes with $\mathrm{pH}$ buffered solutions ranging from $\mathrm{pH}$ 5-8 showed that protonation did not play a role in the intraparasitic $C_{\text {GREEN }}$ distribution. One study 


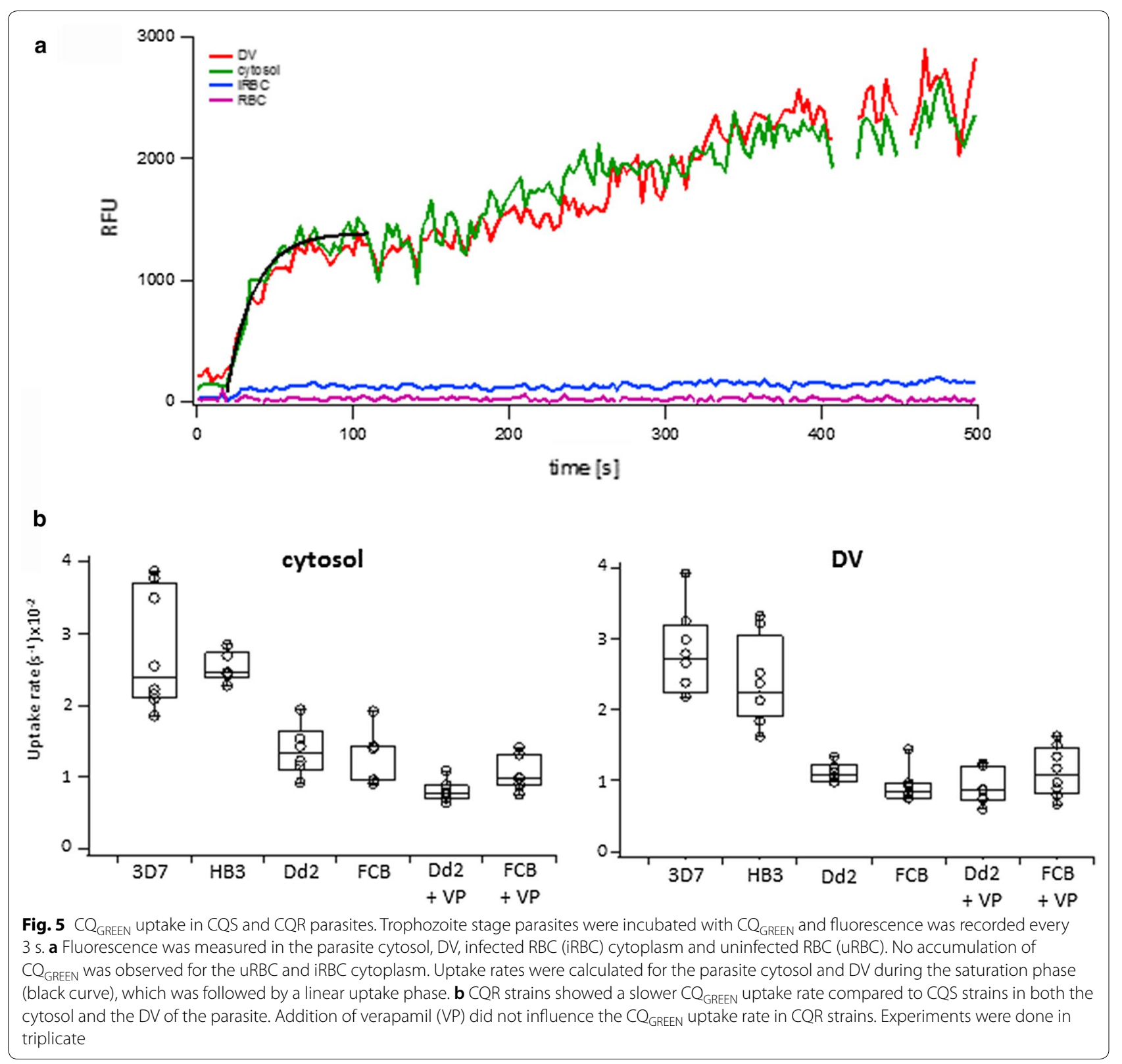

used microsomes to resemble events occurring in the DV and reported accumulation of $\mathrm{CQ}_{\mathrm{GREEN}}$ fluorescence in these microsomes [12]. They did not use intact parasites in their experiments and the data does not support their assumption that $\mathrm{CQ}_{\mathrm{GREEN}}$ accumulates equally well in the DV of live parasites as it does in microsomes [12].

Fluorometric measurements were performed to verify $\mathrm{CQ}_{\text {GREEN }}$ fluorescence at low $\mathrm{pH}$. Slightly higher fluorescence was observed for $\mathrm{CQ}_{\text {GREEN }}$ at acidic $\mathrm{pH}$ (5.0) compared to neutral $\mathrm{pH}$ (7.0). Therefore, if $\mathrm{CQ}_{\text {GREEN }}$ accumulated in the DV, a fluorescent signal would be expected. The absence of fluorescence in the DV suggests that $\mathrm{CQ}_{\text {GREEN }}$ does not reach the DV. Two reasons for this are possible. First, cleavage of the fluorescent Bodipy moiety from CQ may already occur in the parasite cytosol. This would allow CQ to accumulate in the DV, while the Bodipy moiety remains in the cytosol. In this case, the fluorescence signal does not specify the subcellular localization of CQ but rather only the fluorochrome. Second, the Bodipy moiety alters the intrinsic properties of the substrate and, therefore, prevents its accumulation in the DV. A simple way to elucidate whether the Bodipy moiety gets cleaved is determining fluorescence properties of conjugated versus free acid Bodipy-FL. Since there is a fluorescence shift between free acid Bodipy-FL alone (peak at $512 \mathrm{~nm}$ ) and the Bodipy-tagged $\mathrm{CQ}_{\text {GREEN }}$ (peak 
at $520 \mathrm{~nm}$ ), cleavage of the Bodipy moiety from $\mathrm{CQ}_{\text {GREEN }}$ during the cellular uptake would result in a fluorescence shift to $512 \mathrm{~nm}$ when parasites are treated with $\mathrm{CQ}_{\text {GREEN }}$. For this study, intact $P$. falciparum-infected RBCs were treated with $C_{\text {GREEN }}$ to analyse the potential cleavage of the Bodipy moiety. Although a proportional increase in fluorescence with higher parasitaemia was measured, no shift in the fluorescence peak was observed. Thus, $\mathrm{CQ}_{\mathrm{GREEN}}$ remained intact and functional in live parasites prior to parasite lysis for fluorescence measurements.

Despite the unexpected localization of $\mathrm{CQ}_{\mathrm{GREEN}}$ fluorescence mainly in the parasite cytosol and to a lesser extent in the DV, uptake rates were analysed in two CQS and two CQR strains. Although the fluorescent signal obtained from the DV was weak compared to the cytosol, it was sufficient to calculate the uptake rate for this compartment. CQS strains had approx. twofold higher $\mathrm{CQ}_{\text {GREEN }}$ uptake rates for the cytosol and 2.5-fold higher rates for the DV compared to CQR strains. Addition of verapamil to the $C Q R$ strains did not alter $C_{\text {GREEN }}$ uptake rates, suggesting that PfCRT does not play a role in its uptake. This is consistent with the hypothesis that PfCRT is involved in CQ efflux from the DV and is not involved in its uptake [20]. Decreased CQ uptake rates in CQR strains compared to CQS strains may be explained through reduced availability or affinity to an intracellular target, such as free haem [4]. Thus, accumulation of CQ in the DV may contribute to parasite killing, but additional drug targets in the parasite cytosol could also play a role.

\section{Conclusion}

Live cell imaging using fluorescently tagged anti-malarial drugs provides a great tool to elucidate their intracellular localization and give insights into their uptake or efflux rates. The challenge using fluorescently labelled CQ analogues is their sensitivity to $\mathrm{pH}$ and altered intracellular localization, compared to native CQ. Finding fluorescent groups that are more stable at different $\mathrm{pH}$ and do not influence the diffusion properties of the protein would provide a powerful tool in studying the activity of antimalarial drugs. Alterations between drug-sensitive and -resistance strains can be closely monitored to enhance our understanding of resistance mechanisms. Moreover, affinity of $C Q$, or its analogues, to cytosolic proteins may direct research on new anti-malarial drug design away from the DV and increase the focus on cellular pathways in the parasite cytosol.

\section{Abbreviations}

CQ: chloroquine; $\mathrm{CQ}_{\mathrm{GREEN}}$ : chloroquine analogue LynxTag- $\mathrm{CQ}^{\mathrm{TM}}{ }_{\text {GREEN }} ; \mathrm{CQR}$ : chloroquine resistant; CQS: chloroquine sensitive; DV: digestive vacuole; $\mathrm{IC}_{50}$ : half maximal inhibitory concentration; PfCRT: Plasmodium falciparum chloroquine resistance transporter; RBC: red blood cell; iRBC: Plasmodium falciparum infected red blood cell; URBC: uninfected red blood cell.

\section{Acknowledgements}

We would like to acknowledge members of the Rohrbach lab for helpful discussions.

\section{Authors' contributions}

SJR and PR designed the study; SJR performed experiments and quantified the data; SJR and PR wrote and edited the manuscript. Both authors read and approved the final manuscript.

\section{Funding}

This study was supported in part by fellowships from the German Academic Exchange Service (DAAD) (SJR), the Robert P. Harpur fellowship (SJR), and Grants from the Natural Sciences and Engineering Research Council (NSERC) Discovery Grant (PR) and the Canada Foundation for Innovation (CFI) Leaders Opportunity Fund (PR).

\section{Availability of data}

The data are available on request from the authors.

Ethics approval and consent to participate

Not applicable.

\section{Consent for publication}

Not applicable.

\section{Competing interests}

The authors declare that they have no competing interests.

Received: 14 June 2019 Accepted: 28 September 2019

Published online: 07 October 2019

\section{References}

1. WHO. World malaria report 2018. Geneva: World Health Organization; 2018.

2. Sibley $\mathrm{CH}$. Understanding drug resistance in malaria parasites: basic science for public health. Mol Biochem Parasitol. 2014;195:107-14.

3. Cabrera M, Paguio MF, Xie C, Roepe PD. Reduced digestive vacuolar accumulation of chloroquine is not linked to resistance to chloroquine toxicity. Biochemistry. 2009;48:11152-4.

4. Bray PG, Janneh O, Raynes KJ, Mungthin M, Ginsburg H, Ward SA. Cellular uptake of chloroquine is dependent on binding to ferriprotoporphyrin IX and is independent of NHE activity in Plasmodium falciparum. J Cell Biol. 1999;145:363-76.

5. Ginsburg H, Krugliak M. Chloroquine-some open questions on its antimalarial mode of action and resistance. Drug Resist Updat. 1999;2:180-7.

6. Fivelman QL, Adagu IS, Warhurst DC. Effects of piperaquine, chloroquine, and amodiaquine on drug uptake and of these in combination with dihydroartemisinin against drug-sensitive and -resistant Plasmodium falciparum strains. Antimicrob Agents Chemother. 2007;51:2265-7.

7. Lehane AM, van Schalkwyk DA, Valderramos SG, Fidock DA, Kirk K. Differential drug efflux or accumulation does not explain variation in the chloroquine response of Plasmodium falciparum strains expressing the same isoform of mutant PfCRT. Antimicrob Agents Chemother. 2011;55:2310-8.

8. Papakrivos J, Sa JM, Wellems TE. Functional characterization of the Plasmodium falciparum chloroquine-resistance transporter (PfCRT) in transformed Dictyostelium discoideum vesicles. PLoS ONE. 2012;7:e39569.

9. Ch'ng JH, Kotturi SR, Chong AG, Lear MJ, Tan KS. A programmed cell death pathway in the malaria parasite Plasmodium falciparum has general features of mammalian apoptosis but is mediated by clan CA cysteine proteases. Cell Death Dis. 2010;1:e26.

10. Ch'ng JH, Liew K, Goh AS, Sidhartha E, Tan KS. Drug-induced permeabilization of parasite's digestive vacuole is a key trigger of programmed cell death in Plasmodium falciparum. Cell Death Dis. 2011:2:e216.

11. Ch'ng JH, Mok S, Bozdech Z, Lear MJ, Boudhar A, Russell B, Nosten F, Tan KS. A whole cell pathway screen reveals seven novel chemosensitizers to combat chloroquine resistant malaria. Sci Rep. 2013;3:1734. 
12. Loh CC, Suwanarusk R, Lee YQ, Chan KW, Choy KY, Renia L, Russell B, Lear MJ, Nosten FH, Tan KS, Chow LM. Characterization of the commerciallyavailable fluorescent chloroquine-BODIPY conjugate, LynxTag-CQGREEN, as a marker for chloroquine resistance and uptake in a 96-well plate assay. PLOS ONE. 2014;9:e110800.

13. Trager $W$, Jensen JB. Human malaria parasites in continuous culture. Science. 1976;193:673-5.

14. Bacon DJ, Latour C, Lucas C, Colina O, Ringwald P, Picot S. Comparison of a SYBR green I-based assay with a histidine-rich protein II enzymelinked immunosorbent assay for in vitro antimalarial drug efficacy testing and application to clinical isolates. Antimicrob Agents Chemother. 2007;51:1172-8.

15. Smilkstein M, Sriwilaijaroen N, Kelly JX, Wilairat P, Riscoe M. Simple and inexpensive fluorescence-based technique for high-throughput antimalarial drug screening. Antimicrob Agents Chemother. 2004;48:1803-6.

16. van Schalkwyk DA, Nash MN, Shafik SH, Summers RL, Lehane AM, Smith PJ, Martin RE. Verapamil-sensitive transport of quinacrine and methylene blue via the Plasmodium falciparum chloroquine resistance transporter reduces the parasite's susceptibility to these tricyclic drugs. J Infect Dis. 2015:213:800-10.

17. Reiling SJ, Rohrbach P. Monitoring PfMDR1 transport in Plasmodium falciparum. Malar J. 2015;14:270.

18. Kaddouri H, Nakache S, Houze S, Mentre F, Le Bras J. Assessment of the drug susceptibility of Plasmodium falciparum clinical isolates from Africa by using a Plasmodium lactate dehydrogenase immunodetection assay and an inhibitory maximum effect model for precise measurement of the 50-percent inhibitory concentration. Antimicrob Agents Chemother. 2006;50:3343-9.

19. Le Nagard H, Vincent C, Mentre F, Le Bras J. Online analysis of in vitro resistance to antimalarial drugs through nonlinear regression. Comput Methods Programs Biomed. 2011;104:10-8.

20. Cabrera M, Natarajan J, Paguio MF, Wolf C, Urbach JS, Roepe PD. Chloroquine transport in Plasmodium falciparum. 1. Influx and efflux kinetics for live trophozoite parasites using a novel fluorescent chloroquine probe. Biochemistry. 2009;48:9471-81.

21. Martin MM, Lindqvist $\mathrm{L}$. The $\mathrm{pH}$ dependence of fluorescein fluorescence. J Lumin. 1975;10:381-90.

22. Shaner NC, Steinbach PA, Tsien RY. A guide to choosing fluorescent proteins. Nat Methods. 2005;2:905-9.

23. Urano Y, Asanuma D, Hama Y, Koyama Y, Barrett T, Kamiya M, et al. Selective molecular imaging of viable cancer cells with $\mathrm{pH}$-activatable fluorescence probes. Nat Med. 2009;15:104-9.

24. Wunderlich J, Rohrbach P, Dalton JP. The malaria digestive vacuole. Front Biosci. 2012:4:1424-48.

25. Karolin J, Johansson LBA, Strandberg L, Ny T. Fluorescence and absorption spectroscopic properties of dipyrrometheneboron difluoride (BODIPY) derivatives in liquids, lipid membranes, and proteins. J Am Chem Soc. 1994;116:7801-6.

26. Saliba KJ, Folb PI, Smith PJ. Role for the Plasmodium falciparum digestive vacuole in chloroquine resistance. Biochem Pharmacol. 1998;56:313-20.

27. Shore JD, Day DE, Francis-Chmura AM, Verhamme I, Kvassman J, Lawrence DA, Ginsburg D. A fluorescent probe study of plasminogen activator inhibitor-1. Evidence for reactive center loop insertion and its role in the inhibitory mechanism. J Biol Chem. 1995;270:5395-8.
28. Lakowicz JR. Principles of fluorescence spectroscopy. 3rd ed. Berlin: Springer; 2006.

29. Sanchez H, Alonso JC. Bacillus subtilis RecN binds and protects 3 '-singlestranded DNA extensions in the presence of ATP. Nucleic Acids Res. 2005;33:2343-50

30. Sanchez CP, Stein WD, Lanzer M. Is PfCRT a channel or a carrier? Two competing models explaining chloroquine resistance in Plasmodium falciparum. Trends Parasitol. 2007;23:332-9.

31. Yayon A, Cabantchik ZI, Ginsburg H. Susceptibility of human malaria parasites to chloroquine is $\mathrm{pH}$ dependent. Proc Natl Acad Sci USA. 1985;82:2784-8.

32. Krogstad DJ, Schlesinger PH. The basis of antimalarial action: non-weak base effects of chloroquine on acid vesicle pH. Am J Trop Med Hyg. 1987;36:213-20.

33. Geary TG, Jensen JB, Ginsburg H. Uptake of [3H]chloroquine by drugsensitive and -resistant strains of the human malaria parasite Plasmodium falciparum. Biochem Pharmacol. 1986;35:3805-12.

34. Martiney JA, Cerami A, Slater AFG. Verapamil reversal of chloroquine resistance in the malaria parasite Plasmodium falciparum is specific for resistant parasites and independent of the weak base effect. J Biol Chem. 1995;270:22393-8.

35. Verdier F, Le Bras J, Clavier F, Hatin I, Blayo MC. Chloroquine uptake by Plasmodium falciparum-infected human erythrocytes during in vitro culture and its relationship to chloroquine resistance. Antimicrob Agents Chemother. 1985;27:561-4.

36. Reiling SJ, Krohne G, Friedrich O, Geary TG, Rohrbach P. Chloroquine exposure triggers distinct cellular responses in sensitive versus resistant Plasmodium falciparum parasites. Sci Rep. 2018;8:11137.

37. Ginsburg H, Ward SA, Bray PG. An integrated model of chloroquine action. Parasitol Today. 1999;15:357-60.

38. Bray PG, Martin RE, Tilley L, Ward SA, Kirk K, Fidock DA. Defining the role of PfCRT in Plasmodium falciparum chloroquine resistance. Mol Microbiol. 2005;56:323-33.

39. Bray PG, Mungthin M, Ridley RG, Ward SA. Access to hematin: the basis of chloroquine resistance. Mol Pharmacol. 1998;54:170-9.

40. de Dios AC, Tycko R, Ursos LMB, Roepe PD. NMR studies of chloroquineferriprotoporphyrin IX complex. J Phys Chem. 2003;107:5821-5.

41. Fidock DA, Nomura T, Talley AK, Cooper RA, Dzekunov SM, Ferdig MT, et al. Mutations in the P. falciparum digestive vacuole transmembrane protein PfCRT and evidence for their role in chloroquine resistance. Mol Cell. 2000;6:861-71.

42. Lakshmanan V, Bray PG, Verdier-Pinard D, Johnson DJ, Horrocks P, Muhle RA, et al. A critical role for PfCRT K76T in Plasmodium falciparum verapamil-reversible chloroquine resistance. EMBO J. 2005;24:2294-305.

43. Chinappi M, Via A, Marcatili P, Tramontano A. On the mechanism of chloroquine resistance in Plasmodium falciparum. PLoS ONE. 2010;5:e14064.

44. Sanchez CP, Rohrbach P, McLean JE, Fidock DA, Stein WD, Lanzer M. Differences in trans-stimulated chloroquine efflux kinetics are linked to PfCRT in Plasmodium falciparum. Mol Microbiol. 2007;64:407-20.

\section{Publisher's Note}

Springer Nature remains neutral with regard to jurisdictional claims in published maps and institutional affiliations.

\footnotetext{
Ready to submit your research? Choose BMC and benefit from:

- fast, convenient online submission

- thorough peer review by experienced researchers in your field

- rapid publication on acceptance

- support for research data, including large and complex data types

- gold Open Access which fosters wider collaboration and increased citations

- maximum visibility for your research: over $100 \mathrm{M}$ website views per year
}

At BMC, research is always in progress.

Learn more biomedcentral.com/submissions 